\title{
Indoor Air Environment of a Shopping Centre Carpark: CFD Ventilation Study
}

\author{
Rafat Al-Waked $^{1, *}$, Nathan Groenhout ${ }^{2}$, Lester Partridge ${ }^{3}$, Mohammad Nasif ${ }^{4}$ \\ ${ }^{1}$ Department of Mechanical and Maintenance Engineering, German Jordanian University, Jordan \\ ${ }^{2}$ NKG Consulting, Australia \\ ${ }^{3}$ Lehr Consultants International Pty Ltd., Australia \\ ${ }^{4}$ Department of Mechanical Engineering, Universiti Teknologi Petronas, Malaysia
}

Copyright $@ 2017$ by authors, all rights reserved. Authors agree that this article remains permanently open access under the terms of the Creative Commons Attribution License 4.0 International License

\begin{abstract}
Carparks are constructed to provide a certain number of car spaces for visitors, shoppers and/or clients of a commercial facility. The required ventilation system design is generally based on local standards provided by local authorities. The purpose of the current study is to develop a performance based ventilation system for a shopping center carpark. The aim of the study is to undertake computational fluid dynamic (CFD) modelling of the carpark to determine the potential minimum ventilation exhaust rate levels. Results showed that the proposed carpark exhaust system was considered acceptable and no modifications were required. The CO concentration levels in all areas, except within the immediate vicinity of car exhaust plumes, were below $100 \mathrm{ppm}$. The average predicted CO rise was less than $25 \mathrm{ppm}$ across the carpark which is in compliance with the current Worksafe Australia and WHO CO exposure limits. Moreover, results indicated that the $64,000 \mathrm{l} / \mathrm{s}$ exhaust air flowrate was sufficient, and could be reduced to 50,000 l/s. From a financial point of view, it was concluded that the removal of the outlet grilles located at the Southern wall of the Commuters section of the carpark was an acceptable alternative. This cost saving is based on the potential deletion of a fan system, plenum arrangement and shaft which are required as part of the deemed-to-satisfy system design.
\end{abstract}

Keywords IAQ, Carpark, CFD, Ventilation

\section{Introduction}

Motor vehicles are considered to be the major source of air pollution in urban centers. They account for $70 \%$ of oxides of nitrogen ( $\mathrm{NOx}$ ) emissions, $52 \%$ of volatile organic compounds (VOC) emissions and $23 \%$ of fine particulate (PM) emissions [1]. Exposure to high levels of these pollutants could cause health effects such as respiratory and heart diseases [2-4]. The occurrence of lung cancer was high with people exposed to car emissions [5] similar to those of underground carparks [6, 7].

Carpark ventilation systems are used to dilute vehicle emissions to an acceptable level as dictated by the authoritative standards in relation to the location of the carpark. Major vehicle emissions are carbon monoxide (CO), hydrocarbons (HC), $\mathrm{NO}_{\mathrm{x}}$ and $\mathrm{PM}$ (for diesel vehicle only). In areas where cars use gasoline as a fuel, the dilution of CO is seen as the defining parameter for carpark air quality because it is emitted at levels, generally, over twice that of the other contaminants [8-13]. The related Australian Standards require the airflow rate to be based upon the dilution of CO concentrations [14-17]. Therefore, CO concentrations are used to determine the validity of carpark exhaust/ventilation designs [18-21].

Vehicle emission standards in for Australia are set by the Commonwealth Government in the Australian Design Rules (ADRs). Compared to other industrialized nations, Australia is lagging behind in regulating emission standards. For example, the Euro 2 standard was implemented in Europe in 1996 whereas is only implemented in Australia in 2003/04 (ADR 79/00) [1]. The previous ADR for passenger vehicles (ADR37/01) set the same standards as those introduced in the United States in 1981. The latest standard in use is the Euro 4 - Euro 6 standards where it limits the emission of CO from passenger cars to $1.0 \mathrm{~g} / \mathrm{km}$ [22]. This value is much lower than the $2.1 \mathrm{~g} / \mathrm{km}$ of $\mathrm{CO}$ emission based on ADR $37 / 01$ [1] used in the late 1990s and lower than the $2.3 \mathrm{~g} / \mathrm{km}$ of CO emission based on Euro 3 standard [22] used after 2004. This has led the emission standards for new vehicles to become more stringent and the vehicle fleet to be renewed. Therefore, data for calculating vehicle emissions and the corresponding ventilating air demand is continuously updated [22].

Commercial computational fluid dynamics (CFD) models 
have been used as an effective tool to solve the momentum, turbulence and pollution dispersion equations in a complex geometry. Therefore, the use of CFD as a tool to predict the indoor air quality inside carparks is widely spread and accepted [19, 21, 23-26]. The validation of such CFD codes was achieved by comparing simulation results with an already published data from a given carpark [12]. However, CFD commercial packages in use have reached high level of creditability in reporting valid outcomes in relation to carparks. For example, Ho et al. [27] conducted a study on determination of carbon monoxide $\left(\mathrm{CO}_{2}\right)$ levels and thermal environment in an underground car park. They reported that hourly average temperature is correlated with engine operating time fraction, ambient temperature, and historic effect for thermal environment. Both correlations were achieved with the $\mathrm{R}^{2}$ value exceeding $90 \%$. Khalil et. al. [28, $29]$ investigated the performance of the ventilation system of an underground carpark using a steady state CFD simulation. Under Egyptian regulations, the adopted limits for CO concentration shouldn't exceed $50 \mathrm{ppm}$ in the normal operating conditions and $100 \mathrm{ppm}$ in the extreme peak conditions. They have reported that ASHRAE Standard $62-2010$ [30] recommends a ventilation rate of $7.6 \mathrm{~L} / \mathrm{s} \cdot \mathrm{m}^{2}$ or 6 air changes per hour. Furthermore, they conclude that most of carparks at the U.S. uses lower flowrates while maintain a healthy indoor environment.

It can be seen that most of the published carpark CFD investigations were directed to find the optimum ventilation rates for the special case of the already constructed carpark. The current study is taking a similar path in using CFD tools to simulate ventilation system of a shopping center carpark during construction phase. The approach taken to validate the carpark ventilation performance was to model the system to achieve the minimum short term CO levels allowable [14, 15, 31, 32] when using motor vehicle emission data provided by PIARC [33]. The current study will involve the simulation of the partially underground carpark ventilation system:

1. To demonstrate, using CFD, the effectiveness of the proposed carpark ventilation strategy in diluting $\mathrm{CO}$ emissions and to make recommendations for providing performance based ventilation solutions in areas where the deemed-to-satisfy design did not perform adequately.

2. To validate the need for exhaust grilles on all sides of the car park as per the proposed deemed-to-satisfy ventilation system which leads toward financial savings.

3. To determine the potential minimum ventilation exhaust rate levels allowed.

\section{Carpark Layout}

The shopping center carpark under investigation provides parking for 467 cars as depicted by Figure 1. The Retail Basement section of the carpark accommodates up to 237 cars while the Commuters section accommodate up to 230 cars. Due to the dimensions of the carpark sections, the carpark ventilation design requires to ensure that the ventilation system meets the requirements of the Building Code of Australia and Australian Standard 1668.2 [14-17]. The distance that the outdoor air needs to travel across the entire carpark from the Northern or the Eastern boundaries of the Commuters section to the mechanical exhaust grilles at the Southern and Western sides is greater than $75 \mathrm{~m}$. The related standards $[14,15]$ specify that in cases where the distance between the supply and exhaust air is greater than $75 \mathrm{~m}$ "the ability of such 'engineered' systems to effectively dilute polluted air in all parts of the carpark should be demonstrated".

The overall maximum dimensions for the Retail Basement were approximately 122 by $83 \mathrm{~m}$ by approximately $3 \mathrm{~m}$ floor to ceiling height at the walls as shown by Figure 1. There exists a slope along both sides of the Retail Basement, which increase the height of the ceiling from $3 \mathrm{~m}$ at the wall to approximately $5 \mathrm{~m}$ at the open side of the park. The Commuters section of the carpark has similar dimensions with similar slope configurations. In addition, the carpark has two car inlets/exits pairs at the South/ North sides. 


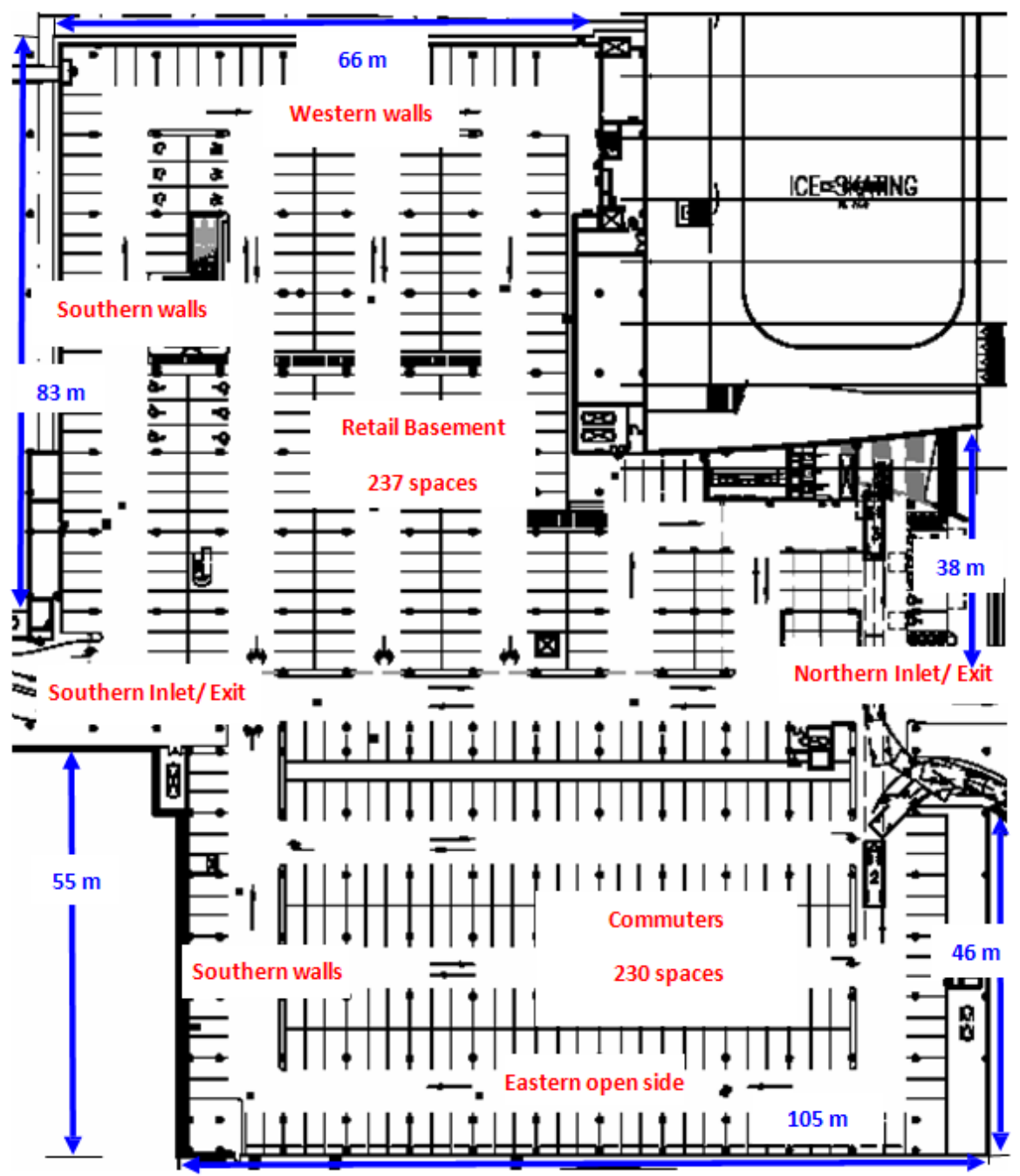

Figure 1. The proposed Shopping Centre carpark layout

The general airflow through the carpark is from open Northern and open Eastern facades of the Commuters carpark to the Retail Basement carpark. This means that the two external sides of the Commuters section are open to the outside air with air traveling distances of much less than $75 \mathrm{~m}$. This fact minimized the need for the provision of mechanical ventilation system and reduced the ventilation flow rate needed when compared with similar number of cars in the underground Retail section [34]. At the Southern side of the Retail section, the entrance/exit opening provides additional source of make-up air. Furthermore, at the Southern and Western underground sides of the Retail section, exhaust grilles extract polluted carpark air and discharge it directly to the outdoors. The ventilation system consisted of a ducted exhaust system with intakes located at high and low levels. In the Retail section, there were 24 exhaust grilles located along the Southern and the Western walls with 900 by $900 \mathrm{~mm}$ dimensions and exhaust flow rate of 2,133 l/s each. In the Commuters section, there were 10 exhaust grilles located along the Southern wall with 900 by $900 \mathrm{~mm}$ dimensions and exhaust flow rate of 1,280 l/s each. To comply with the content of ruling standards [14-17], it is intended to provide $64,000 \mathrm{l} / \mathrm{s}$ of exhaust ventilation: 51,200l/s for Retail section and 12,800 l/s for Commuters section.

\section{Model Description}

The amount of $\mathrm{CO}$ in car exhaust depends on, amongst other things: the age of the car, whether a catalytic converter has been fitted, the engine running temperature (i.e. whether the car is started from cold conditions or not) and the speed of the vehicle. Data obtained from the Permanent International Association of Road Congress Technical Committee on Road Tunnels (PIARC) [22] shows significantly reduced emissions from newer car fleets when compared with the older reported [33]. The calculation scheme of PIARC [22] offers two approaches for estimating vehicle emissions for a certain design year. The first approach is based on using data of 2010 as the base year and adjusted with country specific influencing factors. The second approach allows a detailed emission calculation based on vehicle-specific emission factors where the detailed 
fleet composition for the design year is required.

The CO emission levels listed in Table 1 are used in the current CFD analysis. Newer vehicles have lower emissions than older vehicles, whilst cars that are hot emit less CO than cars that are cold. In Australia, about half of new passenger vehicles sold in any one year are still on the road 20 years later [1]. Therefore, the PIARC data [33] was used to determine emission levels from motor vehicles and was used in conjunction with other available data in order to determine the average age of the fleet [14-17].

Table 1. Vehicle emissions based on reported PIARC data [33].

\begin{tabular}{|c|c|c|c|}
\hline \multicolumn{4}{|c|}{ CO emission rate (g/min) } \\
\hline Age of car (years) & Starting Period & Idling & Driving at $5 \mathrm{~km} / \mathrm{hr}$ \\
\hline$<3$ & 1.7 & 0.33 & 1.08 \\
\hline $3-5$ & 2.76 & 0.56 & 1.80 \\
\hline $5-10$ & 8.43 & 1.68 & 2.53 \\
\hline $10-50$ & 24.2 & 4.83 & 6.90 \\
\hline
\end{tabular}

\subsection{Background Concentrations}

Ambient levels of CO have fallen due to improvements in motor vehicle emission control technology such as the introduction of two-way and three-way catalysts. In the central business district (CBD) of Sydney there has been a continued reduction in CO levels since 1982. The ambient level of CO has dropped from 15 ppm in the 1990s to less than 9 ppm by the year 2016 [35, 36], which is considered to be a conservative value [37]. Nowadays, the CO concentration of ambient fresh air at the intake of the carpark ranges from $1-5 \mathrm{ppm}$ [22].

In times of high vehicle movement, background concentrations may increase around the exhaust grilles and areas of low air movement. This increase would be proportional with low levels around the carpark perimeter and high levels towards the carpark center. Results from all the investigated strategies indicated that even if the outdoor CO concentration levels exceed $20 \mathrm{ppm}$ the CO concentration levels inside the carpark were still within the acceptable limits.

The suitability of the ventilation method in the current study was based on the safe exposure limits listed in Table 2. Based upon these values, the study aims for a 30-minutes average CO concentration of $100 \mathrm{ppm}$ (91 ppm rise) when based upon an ambient CO concentration of $9 \mathrm{ppm}$. It is worth mentioning that the $100 \mathrm{ppm}$ value corresponds to the 1988 WHO recommendation for short term-exposures [38].
However, the most recent design and threshold value for $\mathrm{CO}$ concentration is $70 \mathrm{ppm}$ [22]. Furthermore, to avoid excessive air demands for rarely occurring congestion conditions, a higher CO concentration can be allowed (100 ppm) as reported by PIARC [22].

Table 2. CO concentration exposure limits.

\begin{tabular}{|c|c|c|}
\hline $\begin{array}{c}\text { Concentration } \\
(\mathrm{ppm})[39]\end{array}$ & $\begin{array}{c}\text { Concentration } \\
\left(\mathrm{mg} / \mathrm{m}^{3}\right)[40]\end{array}$ & $\begin{array}{c}\text { Maximum exposure duration } \\
\text { per day (minutes) }\end{array}$ \\
\hline 400 & - & Peak Exposure limit \\
\hline 200 & 100 & 15 \\
\hline 100 & - & 30 \\
\hline 60 & 35 & 60 \\
\hline
\end{tabular}

For the purpose of the current modelling, the background concentration has been set to zero. The average CO concentration rise was limited to $51 \mathrm{ppm}$ to achieve the nominated acceptable level of $60 \mathrm{ppm}$ based on a maximum exposure of one hour in accordance with the current worksafe Australia requirements [39]. These values represent around 200\% of the current world health organization (WHO) CO concentration exposure limits [40].

\subsection{Carpark Design}

The carpark is a mix of Commercial, Retail and Entertainment category carparks and therefore has a mix of usage factors of $0.5,0.75$ and 1.0 , respectively [14-17]. This means that for a commercial carpark, up to $50 \%, 75 \%$ or $100 \%$ of the parking spaces may be emptied or filled within one hour. Australian Standard AS1668.2 [14-17] suggests that in many instances the actual usage factor will be lower. Commercial carparks generally have most car movements in the morning and evening peak hours. Entertainment periods are generally in the evening. Retail is consistent with peaks at late shopping nights. Since cars are starting from cold in the evening, this is considered the worst case for $\mathrm{CO}$ emissions and as such the modelling is based on car movements and exhaust emissions during the Thursday evening peak hour. In addition, the usage factor of 1.0 has been utilized to the whole carpark.

The total number of moving cars that exist at any given time within the carpark depends on the total time of travel for each car as listed in Table 3. The total time of travel has been determined based on: start-up time, travel time based on the average length of travel through the carpark at $6 \mathrm{~km} / \mathrm{hr}$ and exit time. The queuing of cars at the exits is considered not significant as the cars exit the carpark into a side road which then exits onto public roads.

Table 3. Total number of cars exiting the carpar per hour.

\begin{tabular}{|c|c|c|c|c|c|c|c|}
\hline Area & $\begin{array}{c}\text { No of } \\
\text { cars }\end{array}$ & $\begin{array}{c}\text { No of cars leaving } \\
\text { per hour }\end{array}$ & $\begin{array}{c}\text { Time to depark } \\
\text { (sec) }\end{array}$ & $\begin{array}{c}\text { Average distance to } \\
\text { exit (m) }\end{array}$ & $\begin{array}{c}\text { Travel time to } \\
\text { exit (sec) }\end{array}$ & $\begin{array}{c}\text { Time to exit } \\
\text { (sec) }\end{array}$ & $\begin{array}{c}\text { Total time } \\
\text { (sec) }\end{array}$ \\
\hline $\begin{array}{c}\text { Retail } \\
\text { Basement }\end{array}$ & 237 & 237 & 30 & 88 & 60 & 10 & 100 \\
\hline Commuters & 230 & 230 & 30 & 88 & 60 & 10 & 100 \\
\hline Totals & $\mathbf{4 6 7}$ & $\mathbf{4 6 7}$ & & & & & \\
\hline
\end{tabular}




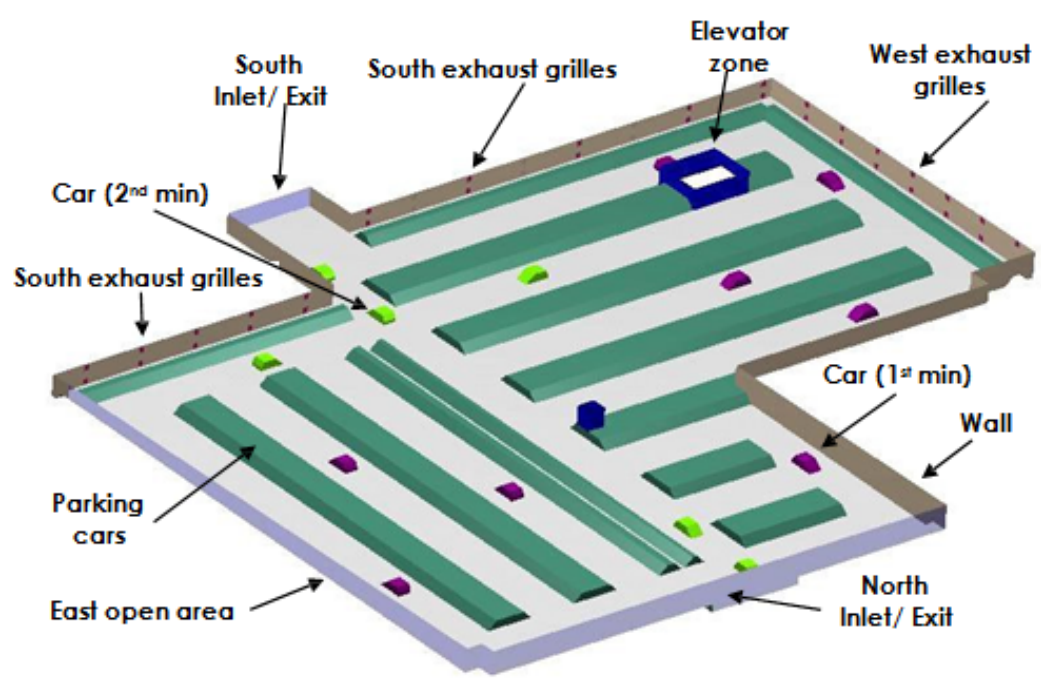

(a)

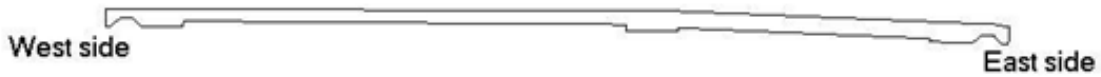

(b)

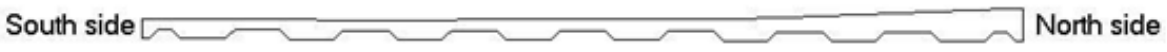

(c)

Figure 2. General view of: (a) the investigated carpark, (b) East-West cross-section and (c) North-South cross-section.

Based on results presented in Table 3, 8 cars exit the carpark every minute. Consequently, the total number of running cars at any instance has been based on maintaining the condition of 8 cars exiting the carpark per minute. The main parameter that determines the number of cars that are running within the carpark is the average distance to exit. The average distance to exit has been calculated based on the carpark dimensions shown in Figure 1 and based on the conservative assumption that the Retail Basement section uses only the Southern exit while the Commuters section uses the Northern exit. Therefore, each car within the carpark has been assumed to travel $88 \mathrm{~m}$ in order to exit the carpark. Consequently, 14 cars were calculated to be moving within the carpark at any instance to satisfy the condition of 8 cars exiting the carpark every minute. Among the 14 cars, 8 cars were running for less than one minute while the other 6 cars were in their second minute of operation. The location of these cars inside the carpark is shown in Figure 2.

\subsection{Car Model}

Car exhausts are modelled as fixed mass flow rates into the carpark at various locations. The flow rate is determined by the engine size and engine speed. However, the $\mathrm{CO}$ concentration is set by the $\mathrm{CO}$ emission rate. This is based on the assumption that an average car has an engine size of 2 liters and running at $1200 \mathrm{rpm}$ when inside the carpark. At every revolution half of the capacity is exhausted, then the exhaust had the following properties:

- $\quad$ Flow rate:

- Exhaust temperature:

- Exhaust pipe diameter:

- Exhaust pollutant properties: Ideal gas with the properties of air at $60^{\circ} \mathrm{C}$.

Research carried out by Logan [41] using car fleet ages based on PIARC data [33] has suggested car ages and percentage among the whole fleet as summarized in Table 4 . This data suggests that most of the car fleet is relatively young and less than five years old [42]. Therefore, the adopted car fleet structure has been assumed to consist of $5 \%, 55 \%$ and $40 \%$ of vehicles in the $10-50,5-10$ and $3-5$ years of age groups, respectively. This is a more conservative make-up than the one produced by Logan [41], thus providing a significant factor of safety. The resultant $\mathrm{CO}$ emission rates based on this assumption are summarized in Table 5.

Table 4. Car fleet structure according to Logan [41].

\begin{tabular}{|c|c|}
\hline Age period & Percentage of cars \\
\hline$<3$ Years & $10 \%$ \\
\hline $3-5$ Years & $50 \%$ \\
\hline 5-10 Years & $30 \%$ \\
\hline 10-50 Years & $10 \%$ \\
\hline
\end{tabular}


Table 5. Weighted CO emissions from the simulated cars based on PIARC [33].

\begin{tabular}{|c|c|c|c|c|c|}
\hline & \multicolumn{3}{|c|}{ Car Age } & \multirow{2}{*}{ Weighted average } & \multirow{2}{*}{ Equivalent } \\
\hline & $10-50$ years & 5-10 & 3-5 years & & \\
\hline Percent of Fleet [41] & $40 \%$ & $55 \%$ & $5 \%$ & & \\
\hline Starting Emissions g/min & 24.2 & 8.43 & 2.76 & 14.5 & 11,188 \\
\hline Driving Emissions g/min & 6.9 & 2.53 & 1.8 & 4.2 & 3,240 \\
\hline
\end{tabular}

\subsection{CFD Solution Parameters}

CFD is a computer based simulation tool for the analysis of complex systems. The type of systems that could be investigated using CFD include fluid flow, particles dispersion and heat/mass transfer. CFD is a powerful tool for assisting in the design and optimisation of ventilation systems. It could be used to model and predict airflow, air quality and temperature within a space. The current carpark has been modelled using the commercial CFD software CFD-ACE+ v2004, from CFD Research Corporation [43]. CFD-ACE + is an unstructured, polyhedral cell flow solver. CFD-ACE+ uses a fully implicit, segregated solver, employing a cell-centred control volume solution technique whereby the partial differential equations of fluid flow are discretised and numerically integrated over the cell volume to yield the variable values at the cell centre.

A three-dimensional CFD pressure based solver, steady-state model of the carpark was developed. The volumetric species transport model was adopted to describe the $\mathrm{CO}$ emissions from cars and dry air gas mixture $\left(\mathrm{N}_{2}\right.$ and $\mathrm{O}_{2}$ ) with the inclusion of diffusion energy source options. As the continuity equation cannot be written in the general conservative form, an alternative method was used for solving the velocity-pressure coupling (the SIMPLEC algorithm [44]). The second order upwind discretization scheme was used with momentum, energy, species and pressure solving equations.

The governing equations of all fluid flow equations, including scalar quantities and pollutant concentrations, could be expressed in the following general conservation form of the transport equation [45]:

$$
\nabla \cdot(\rho \phi \vec{V})=\nabla \cdot\left(\Gamma_{\phi} \nabla \phi\right)+S_{\phi}
$$

where $\phi$ represents the variable of interest, $\rho$ is the density, $\Gamma$ is the diffusion coefficient and $S_{\phi}$ is the source rate per unit volume. From left to right these terms are the convective term, the diffusive term and the source term.

The energy equation in the current CFD model can be written as:

$$
\nabla \cdot(\vec{V}(\rho E+p))=\nabla \cdot\left(k \nabla T-\sum_{i} h_{i} \vec{J}_{i}\right)
$$

where $\mathrm{k}$ is the thermal conductivity, $\mathrm{T}$ is the dry air mixture temperature and $\mathrm{J}_{\mathrm{i}}$ is the diffusion flux of species $i$. The two terms on the right hand side of Eq. (2) represent the energy transfer due to conduction and species diffusion, respectively.

When solving the conservation equations for $\mathrm{N}_{2}, \mathrm{O}_{2}$ and $\mathrm{CO}$, CFD-ACE + predicts the local mass fraction of each species $\left(\mathrm{Yi}_{\mathrm{i}}\right)$ through the solution of a convection-diffusion equation for the ith species. The species conservation equation takes the following general form:

$$
\nabla \cdot\left(\rho \vec{V} Y_{i}\right)=\nabla \cdot \vec{J}_{i}
$$

The diffusion flux of the $i$ th species (N2, $\mathrm{O}_{2}$ or $\left.\mathrm{CO}\right)$ arises due to concentration gradient. By default, the diffusion flux could be written as:

$$
\overrightarrow{\mathrm{J}}_{\mathrm{i}}=-\rho \mathrm{D}_{\mathrm{i}, \mathrm{ma}} \nabla \mathrm{Y}_{\mathrm{i}}
$$

The density of the utilised ideal gas law for an incompressible flow can be defined as:

$$
\rho=\frac{P_{o p}}{\operatorname{RT} \sum \frac{Y_{i}}{M_{w, i}}}
$$

where $\mathrm{R}$ is the universal gas constant, $\mathrm{M}_{\mathrm{w}, \mathrm{i}}$ is the molecular weight of $\left(\mathrm{N}_{2}, \mathrm{O}_{2}\right.$ or $\left.\mathrm{CO}\right)$ and $\mathrm{P}_{\mathrm{op}}$ is the operating pressure which is given the value of the standard atmospheric pressure. Other properties of the dry air mixture were evaluated based on the mass weighted average of the mixture components.

In order to obtain a unique solution of the governing equations (1), (2) and (4) a set of boundary conditions must be provided. The boundary conditions are used to determine the arbitrary functions resulting from integrating the governing equations. The velocity boundary condition is used to define the velocity magnitude and direction of the exhaust air mixture out of the car. Other required inputs at this boundary are: ambient dry-bulb temperature $\left(24^{\circ} \mathrm{C}\right)$ and species mass fractions. The pressure inlet condition is used to model the flow conditions at the Northern and Eastern sides of the carpark. Required inputs into this boundary are: air gage pressure, ambient dry-bulb temperature and species mass fractions. All solid surfaces of carpark wall and cars were modelled using the wall boundary condition. The no-slip condition was enforced where the air velocity magnitude was equalled to zero. Similarly, no heat flux and zero diffusive flux conditions were enforced at this boundary. It is worth mentioning that the values used as 
inputs to these boundary conditions are taken from and calculated based on the quantities listed earlier in the tables.

The accuracy of the CFD solution is dependent upon a number of factors including the assumptions used to define the model, the complexity of the model geometry and the solution grid size. The computational domain in this study consisted of 2.75 million cells of an unstructured, polyhedral cell flow solver. The $k-\varepsilon$ turbulence model represented the most appropriate choice of model because of its extensive use in other applications. No other turbulence model has been developed that is as universally accepted as the $k-\varepsilon$ turbulence model. Buoyancy effects of flow within the carpark were include via the consideration of acceleration due to gravity $\left(9.81 \mathrm{~m} / \mathrm{s}^{2}\right)$. At the open boundaries (North and East), no wind speed was provided and it was assumed to be equal to $0 \mathrm{~m} / \mathrm{s}$.

In normal carpark operation vehicles move in and out of the carpark in random patterns. As cars move through the carpark the $\mathrm{CO}$ concentrations dissipate through diffusion and convection. Vehicle movements induce small scale eddies in the airflow within the laneways whilst the movement of the cars also results in a trail of $\mathrm{CO}$ emissions rather than a single fixed point source [23]. Large-scale convection occurs due to wind gusts and breezes blowing through the carpark, which can either dilute or concentrate $\mathrm{CO}$ emissions depending upon the prevailing conditions and building design.

For this analysis, the model is run as steady state and may be considered to provide a snapshot of the carpark averaged over a minute using fixed point sources emitting CO. This is an important consideration in interpreting the results of the modelling. Based upon the above statements it can be said that results of the simulation are conservative as they do not account for the random movement of CO sources, the dispersion and mixing obtained by movement of cars as they travel around the carpark and wind gusts blowing through the carpark. The average quantity of CO throughout the carpark is representative; however, the peak values in various locations are generally slightly higher than would be expected in reality.

\section{Results}

Three cases were investigated in the current study: base case model (shown by Figure 2) and two other alternatives. The first alternative investigated effects of the removal of the exhaust grilles from the Commuter section on $\mathrm{CO}$ concentration levels inside the carpark. The second alternative was a modification to the first alternative and investigated effects of the reduction of the ventilation flow rate from $64,000 \mathrm{l} / \mathrm{s}$ to $50,000 \mathrm{l} / \mathrm{s}$ CO concentrations.

Contours of CO concentration up to $100 \mathrm{ppm}$ at a height of $1.4 \mathrm{~m}$ above ground level shown by the figures presented in this section (Figure 3-Figure 5). The floor level varies throughout the carpark and therefore indicated heights are approximate. These heights represent the occupied zone of the carpark, which is the region in which most people within the carpark breathe.

\subsection{Base Case}

Both Retail and Commuters sections of the carpark have a design total exhaust flow rate of $64,000 \mathrm{l} / \mathrm{s}$. The 14 cars were modelled to provide $\mathrm{CO}$ sources: 8 cars in the first minute of operation emitting $14.5 \mathrm{~g} / \mathrm{min}$ of $\mathrm{CO}$ and 6 cars in the second minute of operation emitting $4.2 \mathrm{~g} / \mathrm{min}$ of $\mathrm{CO}$.

It can be seen from Figure 3 that most of the carpark has CO concentration below $100 \mathrm{ppm}$. Moderate CO concentrations, i.e. approximately $50 \mathrm{ppm}$, are typical within several car lengths of the operating vehicles and high concentrations, i.e. approximately 100 ppm, were found immediately in the vicinity of the exhaust plumes. The average concentration of $\mathrm{CO}$ across the displayed plane is $18.6 \mathrm{ppm}$. It is clear that air tends to flow toward the Retail carpark outlets rather than the Commuters outlets. This is due to the slope in the floor of the carpark, which results in the South-Western corner of the carpark being the highest point. Hence, the CO concentration at the Commuters section is well below $100 \mathrm{ppm}$.

Results from the base case highlighted an opportunity to reduce the extent of the outlet grilles. Rather than having outlet grilles along the Commuters section Southern wall, results indicated the possibility of eliminating these outlets from the system.

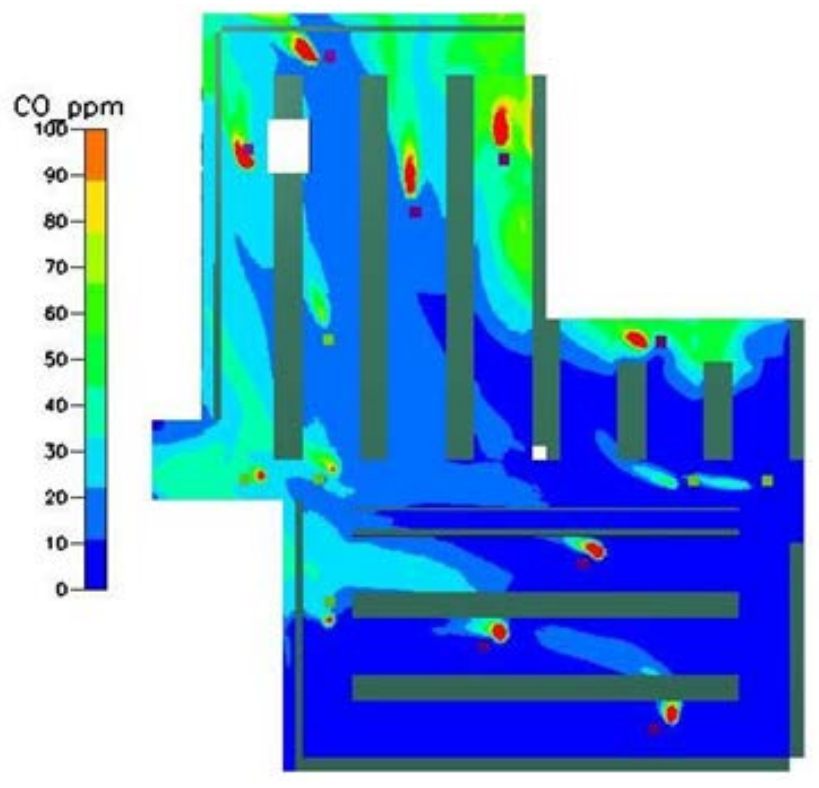

Figure 3. Contours of CO concentration at $1.4 \mathrm{~m}$ above ground level Base Case.

\subsection{Alternative 1- Redesign of Outlet Grilles Location}

The proposed base case design has outlet grilles located at the Southern and Western walls of the carpark as shown by Figure 2. The revised design suggested the removal of the 
outlet grilles at the Southern wall of the Commuters section of the carpark. The total ventilation flow rate of $64,000 \mathrm{l} / \mathrm{s}$ was maintained for this configuration.

It is clear that the removal of the outlet grilles from the Commuters section did not affect the concentration of $\mathrm{CO}$ within the Commuters section as shown by Figure 4. The peak concentration of $\mathrm{CO}$ within the Retail section was found to be less than the limiting value of $100 \mathrm{ppm}$. The average concentration at $1.4 \mathrm{~m}$ height across the whole carpark was $18 \mathrm{ppm}$. This value is lower than the value obtained from the base case. Therefore, having the ventilated air flowing through the Retail section is more favorable as it could be seen from the average CO concentration value. This is because forcing the air to flow in the same direction as the sloped floor creates less recirculation zones throughout the carpark. As a result, the polluted air diffuses in the same direction as the ventilated air flow direction, thus resulting in less polluted areas across the whole carpark.

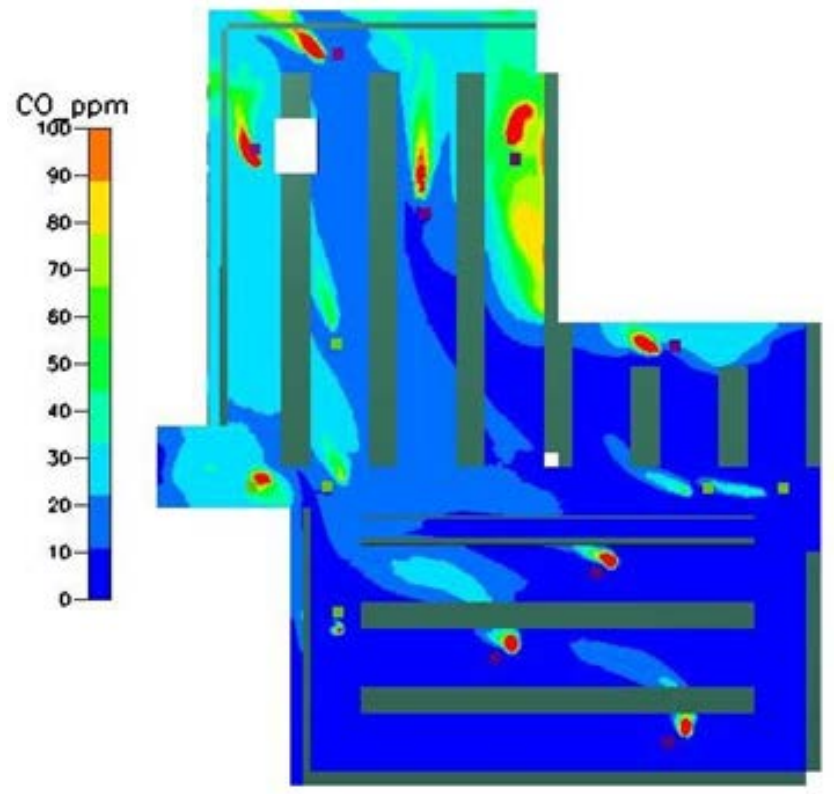

Figure 4. Contours of $\mathrm{CO}$ concentration at $1.4 \mathrm{~m}$ above ground level Alternative 1 Case.

\subsection{Alternative 2- Reduced Airflow}

Results of the base case CFD analysis showed that the $64,000 \mathrm{l} / \mathrm{s}$ was adequate to maintain the $\mathrm{CO}$ concentration level well below the $100 \mathrm{ppm}$ peak limit. Therefore, a reduction of $22 \%$ or $14,000 \mathrm{l} / \mathrm{s}$ in the ventilation airflow rate was examined as an economical alternative. The location of the outlet grilles was maintained similar to Alternative 1 . Similar to the results shown previously in Figure 3 and Figure 4, the concentration of CO remains well below 100 ppm throughout most of the carpark as shown by Figure 5. The average concentration of $\mathrm{CO}$ found to be $21.2 \mathrm{ppm}$ which is the highest among the investigated cases. However, it is below the dangerous concentration level of $100 \mathrm{ppm}$, and well within the $51 \mathrm{ppm}$ average rise allowed per hour.

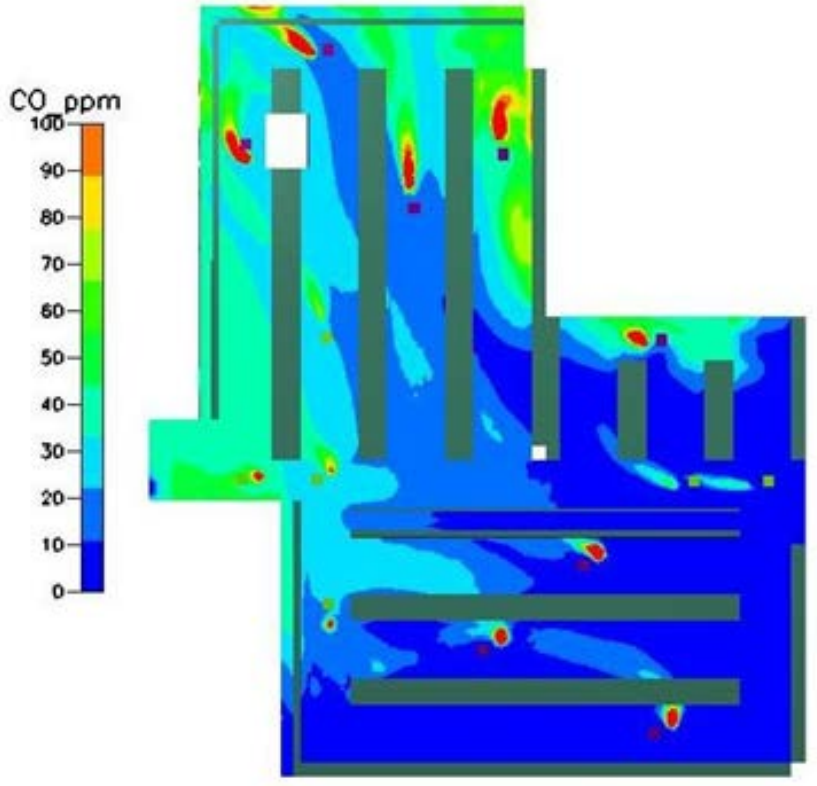

Figure 5. Contours of CO concentration at $1.4 \mathrm{~m}$ above ground level Alternative 2 Case.

\subsection{Comparison}

Analysis of the carpark has been undertaken for a variety of conditions. Airflow speed throughout the carpark was generally $0.1 \mathrm{~m} / \mathrm{s}$ or higher as shown by Figure 6 . This provided good airflow to reduce the pollutant concentration levels, although there were some isolated areas throughout the carpark which had CO concentrations of up to $100 \mathrm{ppm}$. The relatively high speed at the Northern and Southern inlet/ exit is the result of the boundary conditions used in the current CFD model. In reality the air speed at these areas are going to be less than the predicted values unless there were windy conditions.

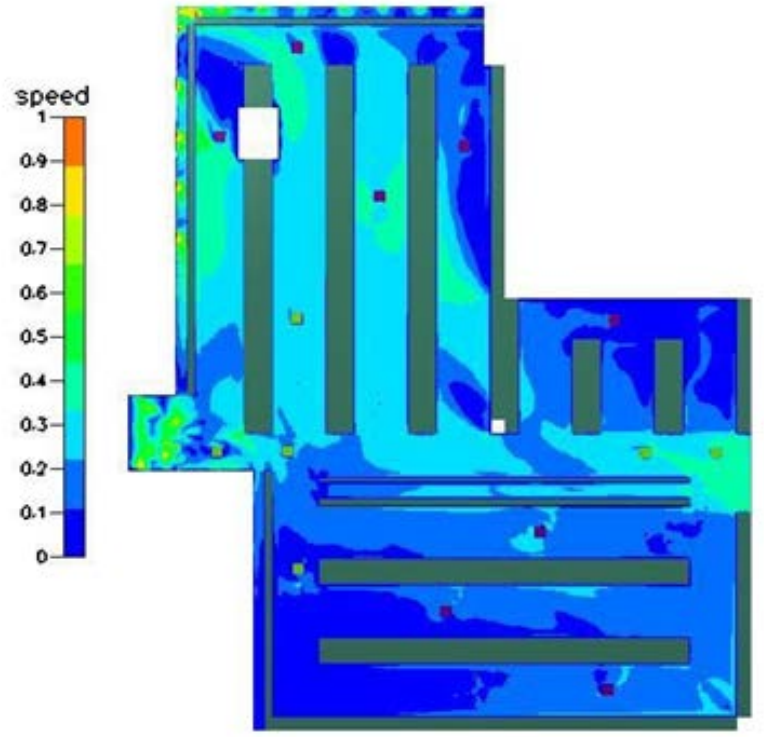

Figure 6. Air speed at $1.4 \mathrm{~m}$ above ground level-Alternative 1 . 


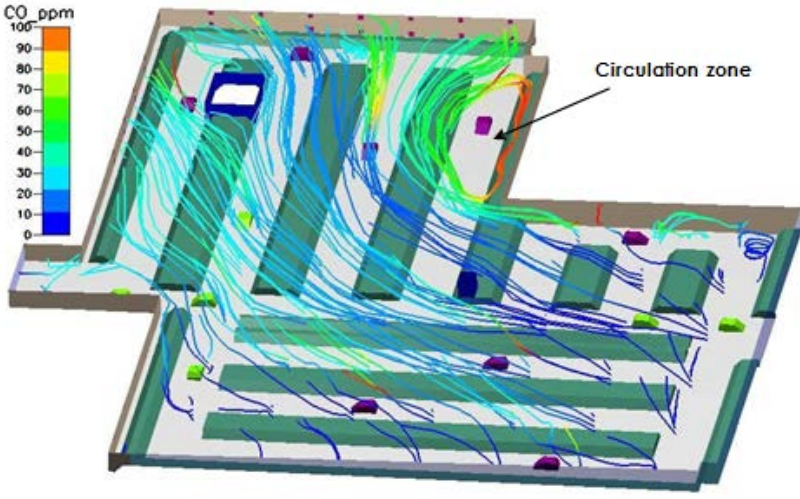

Figure 7. Airflow patterns across the carpark coloured by the CO concentration-Alternative 1.

As the air flew from the Northern/Eastern boundaries toward the Western exhaust grilles side of the Retail section a recirculation zone was developed as shown by Figure 7 . Such a recirculation zone could increase the concentration level to an unacceptable level. Therefore, increasing the mixing of the air in that zone will reduce the risk of high $\mathrm{CO}$ concentrations developing. As a consequence, it is recommended to install mixing fan at the recirculation zone that moves air toward the outlet grille at the Western wall of the Retail section.

Assuming an average of four $90 \mathrm{~m}$ journeys per person per shopping visit between the shopping center carpark doors and his car, the total time of exposure to the carpark environment will be less than 30 minutes. Therefore, the risk of exposure to high CO concentrations within the carpark is mitigated by both the fact that the average level within the carpark is less than 25 ppm rise and peak concentrations, except near the exhaust sources, are well below $100 \mathrm{ppm}$.

Figure 8 shows that for the three investigated ventilation strategies the concentration level of CO is less than $25 \mathrm{ppm}$ across the whole carpark, Therefore, from an air quality point of view the three strategies were all justified and provided acceptable solutions. However, from a financial and energy point of view it can be seen that Alternative 2 provides the best ventilation strategy.

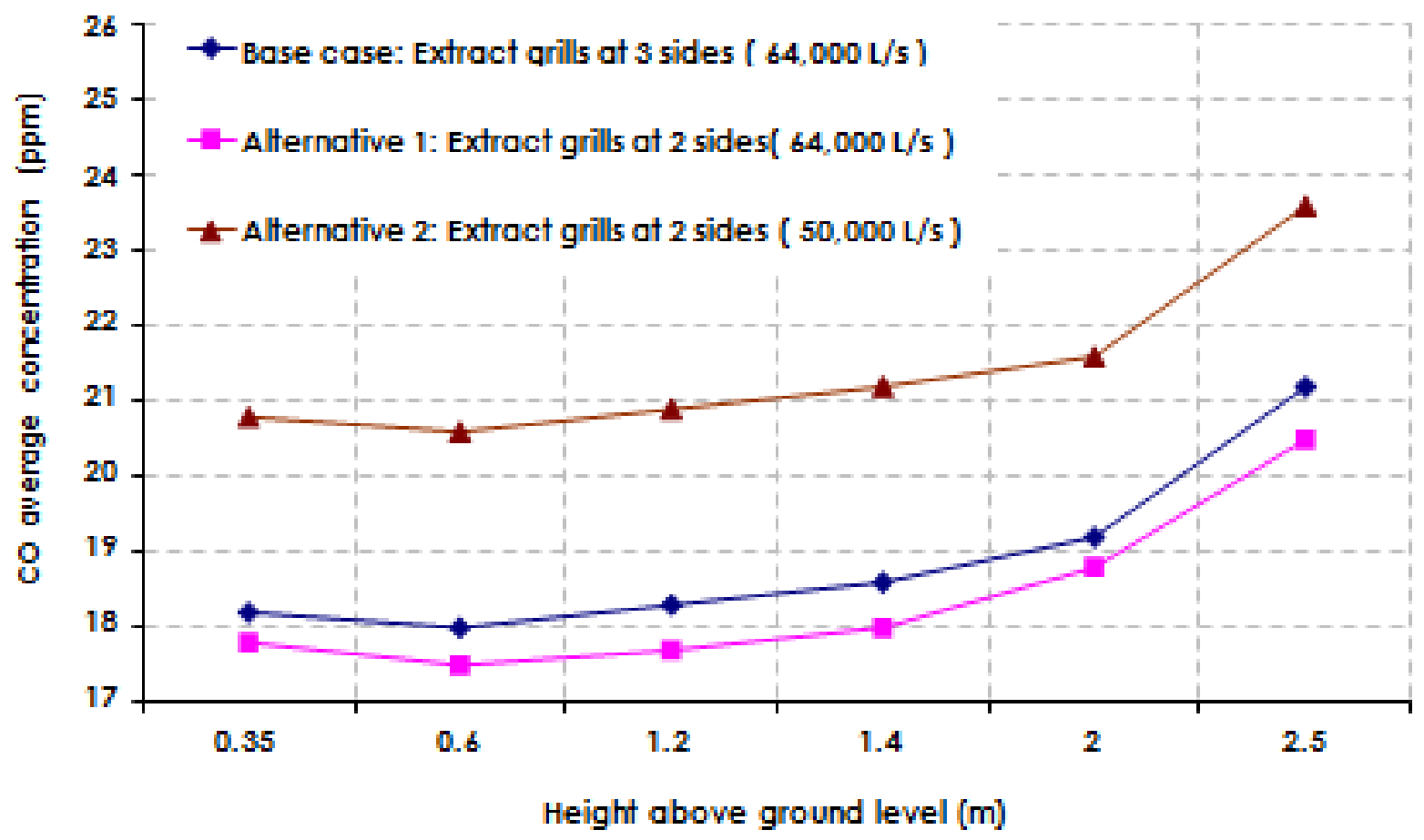

Figure 8. Average concentration of $\mathrm{CO}$ across the carpark. 


\section{Conclusions and Recommendations}

The purpose of the current study was to develop a performance based ventilation system for a shopping center carpark. This was achieved by undertaken CFD simulations of the carpark to determine the potential minimum ventilation exhaust rate levels. Analysis of the carpark were undertaken for a variety of conditions utilizing the CFD approach.

The proposed carpark ventilation system design was considered acceptable and no modifications were required based on the results from the current investigation. The CO concentration levels in all areas, except for the immediate vicinity of car exhaust plumes, were below $100 \mathrm{ppm}$ and the average predicted CO rise was less than $25 \mathrm{ppm}$ across the carpark. In addition, results indicated that the 64,000 l/s exhaust air system was sufficient, and can be reduced to $50,000 \mathrm{l} / \mathrm{s}$ to ventilate the carpark while meeting the indoor air quality requirements.

From financial and energy point of view, it is concluded that the removal of the outlet grilles located at the Southern wall of the Commuters section of the carpark is an acceptable alternative. It is anticipated that the cost savings to the project could be in the order of at least $\$ 50,000$. This cost saving is based on the potential deletion of a fan system, plenum arrangement and shaft which are required as part of the deemed-to-satisfy system design. Therefore, it is recommended to:

- Remove the outlet grilles from the Southern wall of the Commuters section.

- Provide CO concentration sensors at the Retail section of the carpark attached to mixing fans. Once the $\mathrm{CO}$ concentration is higher than $51 \mathrm{ppm}$ the mixing fans are switched on.

- Design the ventilation system with the ability to reduce the flow rate from $64,000 \mathrm{l} / \mathrm{s}$

- to $50,000 \mathrm{l} / \mathrm{s}$ through the use of variable speed drives and $\mathrm{CO}$ sensors.

\section{Acknowledgements}

The support by the Deanship of graduate studies and scientific research of the German Jordanian University (GJU), Jordan are gratefully acknowledged.

\section{REFERENCES}

[1] NSW Environment Protection Authority, Clean cars for NSW. 2003, Environment Protection Authority: Sydney, Australia. p. $1-9$.

[2] Bingheng Chen, Chuanjie Hong, and H. Kan, Exposures and health outcomes from outdoor air pollutants in China. Toxicology, 2004. 198: p. 291-300.
[3] Chan M.Y., Burnett J., and Chow W.K., Personal Exposure to Carbon Monoxide in Underground Car Parks in Hong Kong. Indoor and Built Environment, 1997. 6: p. 350-357.

[4] Hodas N., et al., Indoor inhalation intake fractions of fine particulate matter: review of influencing factors. Indoor Air, 2016. 26: p. 836-856.

[5] Seong-Kyu Park, Shin-Do Kim, and Heekwan Lee, Dispersion characteristics of vehicle emission in an urban street canyon. Science of the Total Environment, 2004. 323: p. 263-271.

[6] Choudhury Gyanranjan Samal, et al., Air Pollution in Micro-Environments: A Case Study of India Habitat Centre Enclosed Vehicular Parking, New Delhi. Indoor and Built Environment, 2013. 22(4): p. 710-718.

[7] Yiu-chung Wong, Della Wai-mei Sin, and Lam Lung Yeung, Assessment of the Air Quality in Indoor Car Parks. Indoor and Built Environment, 2002. 11: p. 134-145.

[8] Pablo Cicero-Fernandez, Jeffrey R. Long, and Arthur M. Winer, Effects of Grades and Other Loads on On-Road Emissions of Hydrocarbons and Carbon Monoxide. Journal of the Air \& Waste Management Association, 1997. 47(August): p. 898-904.

[9] Steven H. Cadle, et al., Real-World Vehicle Emissions: A Summary of the Twelfth Coordinating Research Council On-Road Vehicle Emissions Workshop. Journal of the Air \& Waste Management Association, 2003. 53(February): p. 152-167.

[10] U.S. EPA, Automobiles and Ozone, in Fact Sheet OMS-4. 1993, U.S. EPA.

[11] Gary R. McGaughey, et al., Analysis of motor vehicle emissions in a houston tunnel during the Texas Air Quality Study 2000. Atmospheric Environment, 2004. 38: p. 3363-3372.

[12] Ayari A., Grot R.A., and Krarti M., Field evaluation of ventilation system performance in enclosed parking garages. ASHRAE Transactions, 2000. 106(1).

[13] Chaloulakou A., Duci A., and Spyrellis N., Exposure to Carbon Monoxide in Enclosed Multi-Level Parking Garages in the Central Athens Urban Area. Indoor and Built Environment, 2002. 11: p. 191-201.

[14] Standards Australia, The use of mechanically ventilation and air-conditioning in buildings. Part 2: Mechanical ventilation for acceptable indoor air quality, in AS1668.2 - 1991. 1991, Standards Australia,: Sydney, Australia.

[15] Standards Australia, The use of mechanically ventilation and air-conditioning in buildings. Part 2: Mechanical ventilation for acceptable indoor air quality - commentary in AS1668.2 Suppl1 -1991. 1991, Standards Australia,: Sydney, Australia.

[16] Standards Australia, The use of mechanically ventilation and air-conditioning in buildings. Part 2: Mechanical ventilation for acceptable indoor air quality, in AS1668.2 - 2002. 2002, Standards Australia: Sydney, Australia.

[17] Standards Australia, The use of mechanically ventilation and air-conditioning in buildings. Part 2: Mechanical ventilation for acceptable indoor air quality - commentary in AS1668.2 Suppl1 - 2002. 2002, Standards Australia,: Sydney, Australia.

[18] El Fadel M., et al., Carbon Monoxide and Volatile Organic 
Compounds as Indicators of Indoor Air Quality in Underground Parking Facilities. Indoor and Built Environment, 2001. 10: p. 70-82.

[19] Fernandes R. and Henriques D., Indoor Car Parks - CFD Application, in $V$ European Conference on Computational Fluid Dynamics (ECCOMAS CFD 2010), Pereira J.C.F. and Sequeira A., Editor. 2010: Lisbon, Portugal

[20] Julian D. Marshall, et al., Inhalation of motor vehicle emissions: effects of urban population and land area. Atmospheric Environment, 2005. 39: p. 283-295.

[21] Moncef Krarti and Arselene Ayari, CFD Analysis of Ventilation System Performance for Enclosed Parking Garages. ASHRAE Transactions, 2003. 109: p. 21-29.

[22] Working Group 4 of the Technical Committee C4 of the World Road Association PIARC, Road tunnels: Vehicle emissions and air demand for ventilation. 2012: Niveau 2, France.

[23] Gidhagen L., et al., Simulation of NOx and ultrafine particles in a street canyon in Stockholm, Sweden. Atmospheric Environment, 2004. 38: p. 2029-2044.

[24] Se-Jin Ahn, et al., Study of Securing Required Ventilation Rates and Improving Mechanical Ventilation Systems for Underground Parking Lots. Journal of Asian Architecture and Building Engineering, 2016. 15(3): p. 659-665.

[25] Adil Eshack, et al., Monitoring and simulation of mechanically ventilated underground car parks. Journal of Thermal Engineering, 2015. 1: p. 295-302.

[26] Papakonstantinou K., et al., Air quality in an underground garage: computational and experimental investigation of ventilation effectiveness. Energy and Buildings, 2003. 35: p. 933-940.

[27] Ho J.C., Xue H., and Tay K.L., A field study on determination of carbon monoxide level and thermal environment in an underground car park. Building and Environment, 2004. 39(1): p. 67-75.

[28] Essam E. Khalil, et al., Investigation of Ventilation System Performance of Tahreer Car Park Using CFD. Journal of Energy and Power Sources, 2015. 2(2): p. 81-89.

[29] Sherif M. Gomaa, et al., Ventilation System Design for Underground Car Park. Open Journal of Technology \& Engineering Disciplines, 2015. 1(1): p. 30-41.

[30] ANSI/ASHRAE, Standard 62-2010, Ventilation for Acceptable Indoor Air Quality. 2010, ASHRAE: Atlanta, U.S.

[31] NSW Environment Protection Authority, Approved methods and guidance for the modelling and assessment of air pollutants in New South Wales. 2001, Environment Protection Authority: Sydney, Australia. p. 1-50.

[32] NSW Environment Protection Authority, Approved methods and guidance for the modelling and assessment of air pollutants in New South Wales. 2016, Environment Protection Authority: Sydney, Australia. p. 1-56.

[33] Permanent International Association of Road Congress (PIARC), Road Tunnels, Emissions, Ventilation, Environment'. 1995.

[34] Moncef Krarti and Arselene Ayari, Ventilation for Enclosed Parking Garages. ASHRAE Joumal, 2001(February): p. 52-55.

[35] NSW Environment Protection Authority, Action for Air - NSW Government. 2002, Environment Protection Authority: Sydney, Australia. p. 1-21.

[36] State of NSW, Clean Air for NSW - Consultation Paper. 2016, NSW Environment Protection Authority and Office of Environment and Heritage: Sydney, Australia. p. 68.

[37] Chan C., A performance-based approach to carpark ventilation design. AIRAH Journal, 2001. June: p. 17-21.

[38] WHO, Air quality guidelines for Europe, World Health Organization, in European series, no ${ }^{\circ}$ 23s. 1988: WHO regional publications.

[39] Worksafe Australia, Exposure Standards for Atmospheric Contaminants in the Occupational Environment. 1990, Worksafe Australia: Sydney, Australia.

[40] The WHO European Centre for Environment and Health, WHO guidelines for indoor air quality: selected pollutants, in WHO guidelines. 2010: World Health Organization (WHO), Bonn. p. 484.

[41] Logan S., Performance-based building codes: opportunities for innovative engineering. AIRAH Journal, 1999. December p. 26-31.

[42] Australian Bureau of Statistics media release on Australia's motor vehicle fleet larger and younger 2002, Australian Bureau of Statistics Sydney, Australia.

[43] CFD Research Corporation CFD ACE User Manual. Vol. 2. 2002, Cummings Research Park, Huntsville, Alabama: CFD Research Corporation

[44] Van doormal J.P. and Raithby G.D., Enhancements of the SIMPLE Method for Predicting Incompressible Flows. Numerical Heat Transfer, 1984. 7: p. 147-163.

[45] Versteeg H.K. and Malalasekera W., An Introduction to Computational Fluid Dynamics. 1995. 